\title{
Differentiation of autochthonous figs from northwestern Morocco with morphological criteria
}

\author{
El Oualkadi A*, Hajjaj B*
}

*INRA- Regional Agricultural Research Center of Tangier, Morocco

Corresponding author. E-mail: ai.oualkadi@gmail.com

\begin{abstract}
The importance varietal diversity of fig tree in the traditional agro ecosystems of the Riffian Mountains remains ignored. To evaluate it, a prospection and characterization were carried out in North West of Morocco. Seventy-five morphological parameter traits were used to characterize the fig accessions. In the first way of hierarchical clustering, the fig accessions were distributed into three main groups. The groups were very heterogeneous and include many clusters separate under tow or more clusters. Thus, it could be concluded that there are a wide range of variability within the cultivated fig accessions under current study. This diversification could enrich the genetic base of this genus and required more studies to achieve the maximum usefulness from this diversification.
\end{abstract}

Keywords-Fig, morphology, diversity, cluster analysis, Morocco.

\section{INTRODUCTION}

Ficus carica $L$. is a diploid species $(2 \mathrm{n}=26)$ [1] that belongs to the Moraceae family. It is characterized by the presence of latex in all parts of the plant. The fig is probably the oldest cultivated crop [2], being widely used as a fruit tree in the eastern Mediterranean regions of Europe and Africa and in southwestern Asia [3]. It is the only species of this family cultivated for its edible fruits [1], [4]. In Morocco, the cultivation of the fig tree is ancestral, the villagers of some production areas (Taounate, Chaouen, Ouezzane) claim that its culture is very old and that the dried fruit traded with cereals, from the Gharb. Its cultivation, which once covered a number of flat lands, is currently limited to hills, sloping land and housing. Indeed, this fruit tree is considered secondary and sometimes grown on the edges of orchards to protect them. The fruits are mainly destined for the local market and eaten fresh or dried. This Mediterranean fruit has been linked and has been classified as a minor species despite the role it can play in the development of many areas, especially with the drought and the reduction in the cold availability necessary for fruiting. Intensive fruit species such as apple, peach, pear, etc. The marginalization of the $F$. carica culture exposes the species to severe genetic erosion. It is therefore imperative to put in place a safeguarding strategy aimed at preserving and protecting this heritage.

The varietal heritage of the fig tree (Ficus carica $L$ ) on the Mediterranean scale consists of a few hundred varieties whose genetic diversity has been characterized essentially morphologically [4], [5]. Several studies have reported the use of morphometric and pomological parameters as well as isozyme markers to discriminate fig cultivars [6], [7], [8]. In Morocco, the first work concerning the pomological description of fig tree varieties was made by [9] but from surveys limited to the Chefchaouen region. In order to analyze the constraints affecting the production and marketing of figs, important factors for the development of this sector, particularly the knowledge and characterization of local varieties, must be taken into account. In this context, a study identifying the differentiation of local varieties using morphological parameters was carried out in the northwestern region of Morocco.

\section{MATERIAL AND METHODS}

\section{Plant material}

The study looked at 96 ecotypes of fig trees prospected in northern Morocco. It is about 49 indigenous figs, well spread in the orchards of northern Morocco (Table.1). The work was based mainly on surveys carried out in 14 stations in four large areas in the north - west of the country. These stations were chosen according to the importance of fig orchards in agrosystems (Fig. 1).

- Beni Ahmed area: characterized by its richness in fig and caprifiguier as well as a good knowledge of cultivation techniques in particular caprification. 
- Areas of Moukrisset, Zoumi and Oued Laou: areas rich in figs with very diversified varieties, but with a lack of knowledge of caprification techniques.
- Khmiss anjra area: is a new and much diversified variety of resources especially in Douar Tafza, this area is also characterized by a neglect of caprification.

Table.1: List of varieties studied

\begin{tabular}{lll}
\hline & \multicolumn{2}{l}{ The main varieties } \\
\hline Rhoudane & Saadi & Jouhri \\
Gaouizi & Lemti & Ournakssi \\
Ferzaoui & Sinani & Kharar \\
Baghi assal & Achir & Hafer elbrel \\
Harchi el khal & Hafri & Sbaa ou rhgoud \\
Meltoufa & Chitoui & Kohli \\
Kharaza & Bakour & Zerki \\
Tahadakte & Larchan & Tbantou \\
Tabli & Mouslikh & Sibti \\
Hazouta & aroui & Kourti \\
Lmdar & L'khoumbiz & Silfaf \\
L'hmar & Lndbar & Smouni \\
Fassi & L'beidi & Khoumsi \\
El messari & harchi lbeid & Ounk Hmam \\
Makoutia & L'mdar eL khal & Ozilane \\
Qouti & Maalmouss & \\
Lassoune & Zenfoukh & \\
\hline
\end{tabular}
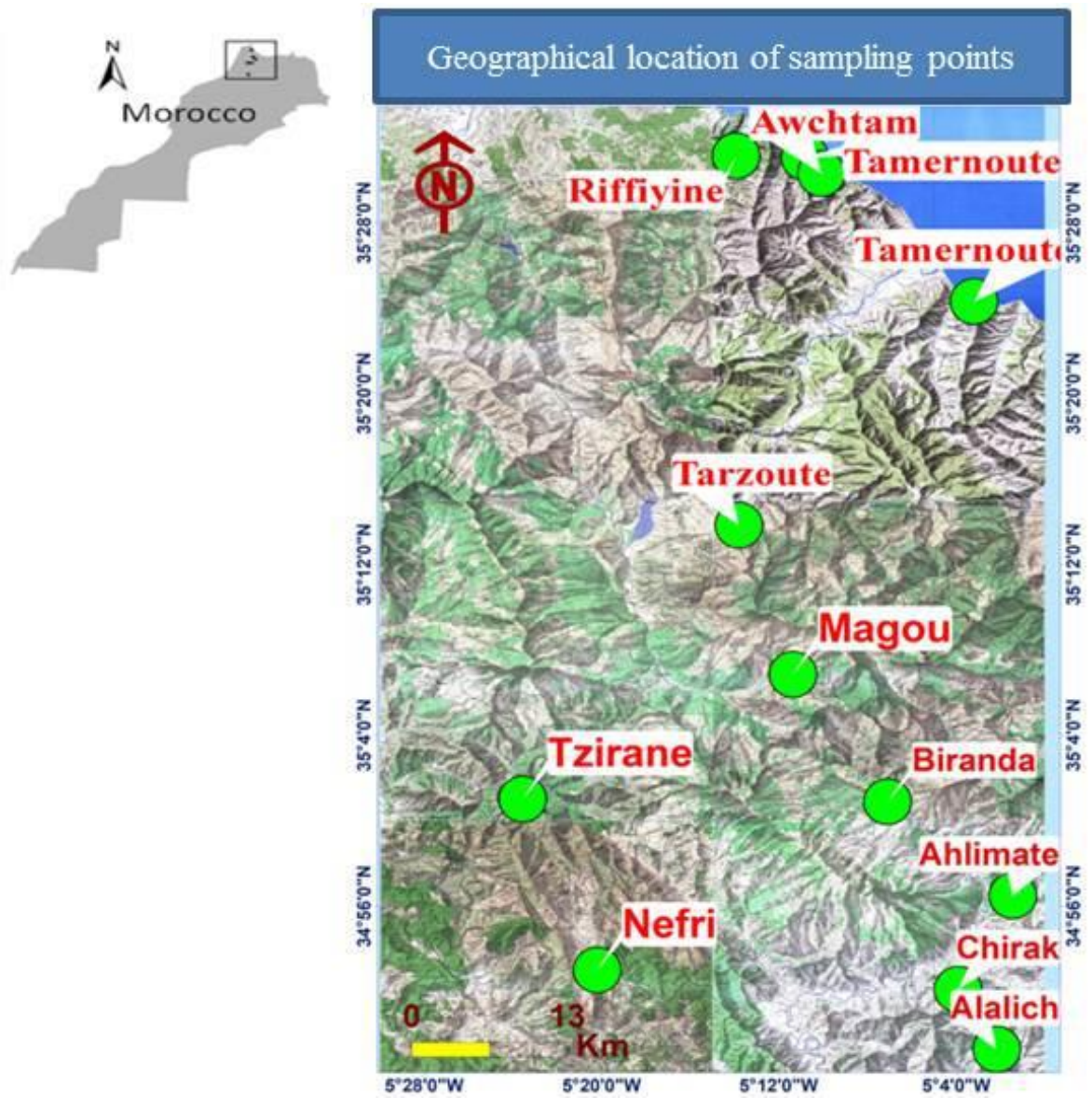

Fig. 1: Localization of the sites prospected 


\section{Morphological character}

The characteristics studied concerned the vegetative development of the tree and, in particular, the measurement of certain parameters characterizing the growth of leaves and shoots developed during the years 2015 and 2016. For each ecotype, the measurements were carried out on two trees and, for each tree, six shoots selected on the south, north-east and north-west sides, at the rate of two shoots per exposure.

We took into account 3 characters: tree habit, leaf type and lobes. For each character, the different modalities are considered (Table 2).

Harbor of the tree:

It corresponds to the general appearance of the tree, there are 5 cases:

Erected: The outer shape of the set of leaves on the tree forms an angle of $60^{\circ}$,

Semi-erect: The outer shape of all leaves on the tree forms an angle of $80^{\circ}$,

Compact: The outer shape of all leaves on the tree forms an angle of $90^{\circ}$,

Spread: The outer shape of the set of leaves on the tree forms an angle of $100^{\circ}$,

Falling: The outer shape of all leaves on the tree forms an angle of $120^{\circ}$.

Type of leaves:

This character corresponds to the number of leaves divided by 5 cases: leaves of a single division, leaves little divided, leaves moderately divided, leaves divided, leaves very divided:

Lobe :

The lobes of fig leaves differ in their depth, so we can distinguish leaves with lobes: very shallow, shallow, medium, deep, very deep.

Table. 2: Morphological characters studied

\begin{tabular}{ll}
\hline Character & Modality \\
\hline Tree port & Erected \\
& Semi erected \\
& Compact \\
& Spread \\
& drooping \\
\hline Sheet type & 1 piece \\
& Little divided \\
& Middle divided \\
& divided \\
& Very divided \\
\hline Lobe & Very little deep \\
& Shallow \\
& Middle Deep \\
& Very deep \\
\hline Fruit general appearance
\end{tabular}

For the general appearance of fruits,

a set of qualitative and quantitative characteristics has been studied, several modalities have been taken according to each parameter (Table 3).

Table. 3: Fruits General Appearance

\begin{tabular}{ll}
\hline Character & Modality \\
\hline \multirow{3}{*}{ Average height } & Very small \\
& small \\
& Bverage \\
& Very big \\
& Very light \\
& Lightweight \\
Average weight & Way \\
& Heavy \\
& Very heavy \\
\hline \multirow{3}{*}{ Skin } & Very delicate \\
& Little Delicate \\
& hairy \\
& No Pubescente \\
& Round \\
Mountain peak & Dish \\
& flattened \\
& Spherical \\
& egg-shaped \\
& pyriform \\
& Turbiniforme \\
& Squash \\
\hline &
\end{tabular}

External and internal characteristics of the fruit

For the general appearance of the fruit, 10 quantitative and 12 qualitative characters were studied. For the external characters of the fruit (Table.4): 35 qualitative and 3 quantitative characters, while for the internal characters of the fruit, 32 qualitative characters (Table.5).

Table. 4: The external characters of the fruit

\begin{tabular}{ll} 
Character & Modality \\
\hline Epidermis \begin{tabular}{l} 
color \\
\cline { 2 - 2 }
\end{tabular} & Light green \\
\cline { 2 - 2 } & Yellow \\
\cline { 2 - 2 } & Green yellow \\
\cline { 2 - 2 } & Grey \\
\cline { 2 - 2 } & Prown \\
\cline { 2 - 2 } & Darple \\
\cline { 2 - 2 } & Violet tied dark wine \\
\cline { 2 - 2 } & Greenish \\
\cline { 2 - 2 } & Golden yellow \\
& Red-brown
\end{tabular}




\begin{tabular}{|c|c|}
\hline & Black purple \\
\hline & Violet - red \\
\hline & Brown gray \\
\hline & Purple \\
\hline & Uniformly dark \\
\hline Eye & Closed \\
\hline & Open \\
\hline & Half open \\
\hline & small \\
\hline & Big \\
\hline & $\begin{array}{l}\text { Providing } \\
\text { duplication }\end{array}$ \\
\hline Peduncle & Variable \\
\hline shape & Long and thin \\
\hline & Short and thick \\
\hline Col & strong \\
\hline & Long \\
\hline & Well distinct \\
\hline & Contrasted to the body \\
\hline & Very affected \\
\hline & $+/-$ marked \\
\hline & Thick \\
\hline cracks & Low Importance \\
\hline & absent \\
\hline & Longitudinal \\
\hline Average & small \\
\hline size of the & Average \\
\hline ostiole & big \\
\hline
\end{tabular}

\begin{tabular}{ll} 
Character & Modality \\
\hline Placenta & Yellowish-white \\
& Greenish white \\
\hline Pulpe & Salmon pink \\
& Black violet \\
& Red \\
& purplish \\
& Pink yellow \\
& Amber \\
& Amber rose \\
& Pale yellow \\
& Red brunette
\end{tabular}

Hot pink

Dark purplish red

\begin{tabular}{ll}
\hline $\begin{array}{l}\text { Abundance } \\
\text { seeds }\end{array}$ & $\begin{array}{l}\text { Low } \\
\text { Average } \\
\text { important }\end{array}$ \\
\hline Seed size & Low \\
& Average \\
& important \\
\hline Perfume of the & Low perfume \\
fig & fragrant \\
& Very fragrant \\
\hline vesicles & fines \\
& Pretty fine \\
& Grosses \\
\hline Quality & Poor \\
& Fair \\
& Pretty good \\
& good \\
& excellent \\
\hline State of the fig & Fresh fig \\
& Dried fig \\
\hline
\end{tabular}

\section{Statistical analyzes}

In order to facilitate the acquisition and processing of data, each modality has been assigned a code. The data processing is carried out using the NTSYSpc software for the UPGMA analyzes of similarities and algorithm for the construction of the clusters.

\section{RESULT AND DISCUSSION}

Port of tree :

According to surveys conducted in the region, most of the trees have a semi-erect habit (48.98\%, effective 24$)$, and $34.70 \%$ have a spreading habit (number 17), the others have a falling port $10,20 \%$ (effective 5) and $6.12 \%$ of the trees have a compact habit, while erect varieties have not been observed. [10] have shown that the variability of the vigor and the habit of the fig tree is due to a strong reiteration of the growth which is accompanied by a significant collapse of the branches. The carrying of the tree is also heritable and this heritability can change according to genotypic diversity and ecological conditions [11]. 


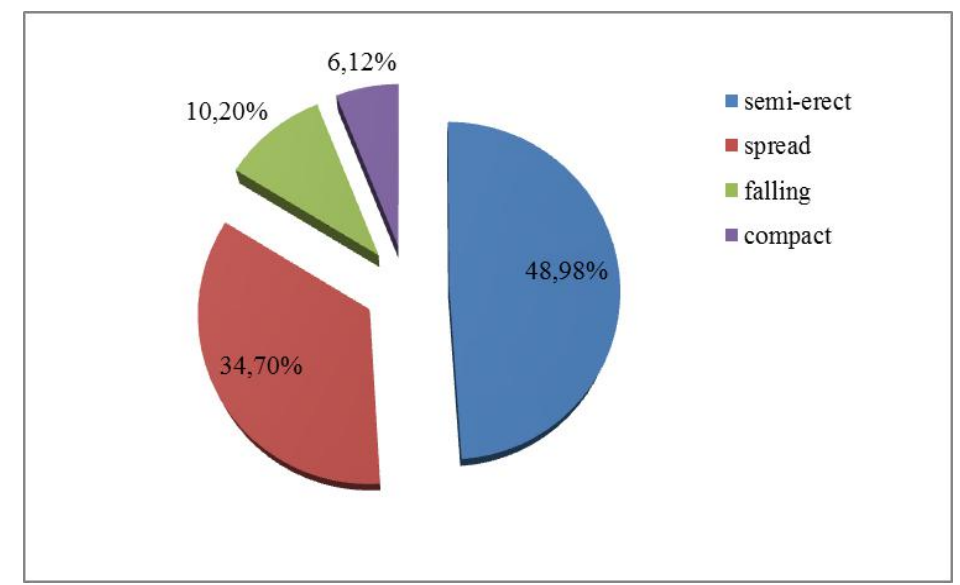

Fig .2 : port of tree

Type of sheet:

The importance of the morphological characteristics of the leaves (Fig. 4) for the varietal differentiation of the fig tree has been the subject of much research [12] and [13]. These traits are very important for the selection of genotypes by arborists and breeders [14].

For this trait, it was noted that the varieties' maturity is divided (63.27\%, effective 31 ), $22.45 \%$ have medium division leaves, $12.24 \%$ have very divided leaves and 2.04 $\%$ have poorly divided leaves, whereas no variety has leaves with a single division. These values are different (14 to 21) from those recorded by [15] but close (6 to 13) to those of [16]. Nevertheless, the differentiation of fig varieties with their leaves, especially in the number of lobes [17] and the thickness of the petiole is difficult because they are polymorphic within the same individual.

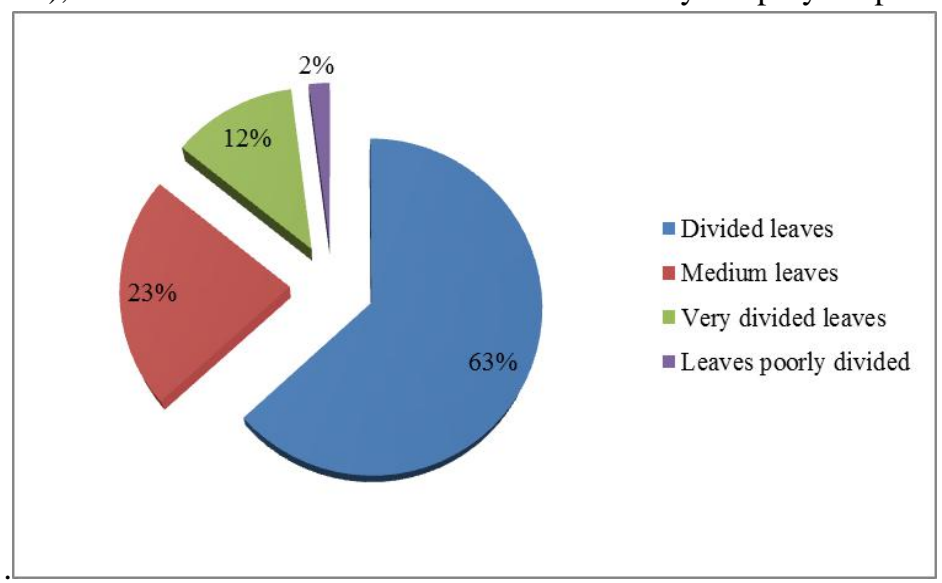

Fig.3: types of leaves

Lobe:

The study of the morphology of the leaves of the varieties showed that $53.06 \%$ of the varieties have a deep lobe (effective size 26), 28.58\% of the varieties have an average lobe (effective size 14), while $10.20 \%$ have a shallow lobe and $8.16 \%$ have a very deep lobe (effective 4). [18] consider that the length of the petiole, the number of lobes per leaf, the length, the width and the leaf area are important parameters for the phenotypic analysis of the fig tree, whereas for [19] they are the form of the base of the leaf, the position of the small side lobes, the degree of approval, and the number and shape of the lobes that are important. In Turkey, [16] found that the color of the petiole is a character that can also change according to the type of fig tree, the cultivar and the conditions of the environment. 


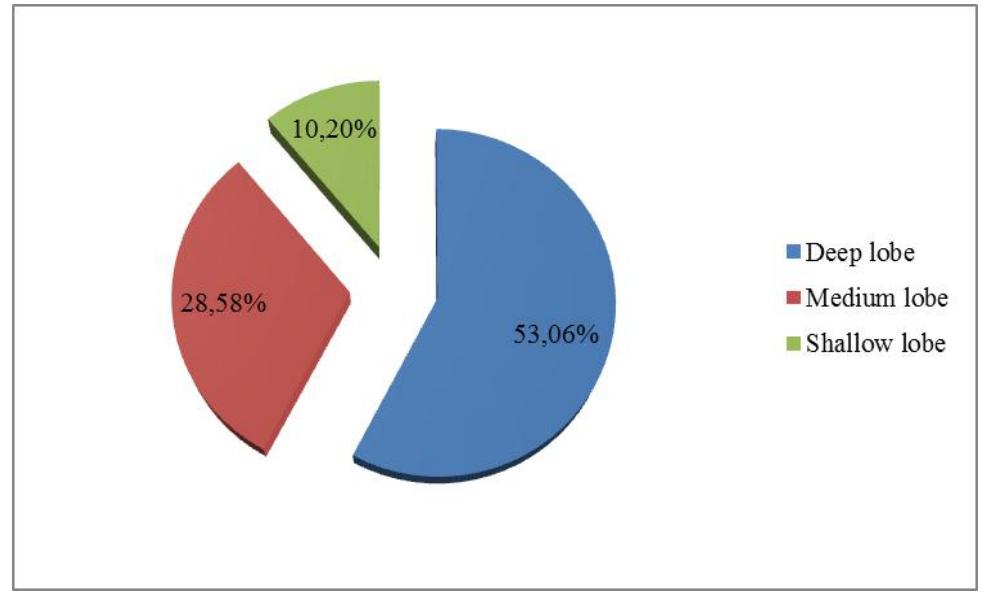

Fig.4: The different types of lobes

\section{Hierarchical classification}

In the first way of hierarchical clustering, the fig accesses were distributed into three main groups. The first group includes four clusters separate under two clusters. The first cluster included Rhouddane accessions, Baghi assal and Harchi lkhal, the second cluster included accessions, Lfassi, Lhmar. The third group was heterogenous (Fig.5).The analysis of the data shows that these types have a great variability as well as the variety. The varieties which bear the same name, with the same morpholigical characters, but it is a general case. We think that they may be in certain cases different varieties but bearing the same name (homonymy) or on the contrary (synonymy). As they can be in other cases polymorphic varieties, polyclonal nature of the varieties is shown in the evaluation of the national collection [20]. It is thus necessary to record the importance of the problems of denomination of the species listed in the prospected area. These problems are due to local names which vary from one locality to another and the absence of the syntheses and varietal characterization. 
Lrast

Betch
Harri

Harr

Harr

Baghi assat

Hazouta

Baghi assai

Fhoudane

Fhoudane

Fhoudan

Gaouizi

Chitoui

Gaoviz

Harchi El kh

Rhoudane

Harra ou terzaouto

Harchi El kh

Laresar

Herich

sarar

strat

makoutio

Koti

Koth

Lemti

Lrast

Lrasi

Herion

Lassour

Journ

Ounk Hmam

Zentoukh

Hatra ou rerzaoui

Lmdar

Ournaks:

khoumst

Maatmouse

Joutri

Kraraz

Bakour

Zerki

Achit

Ounk Hmam

Kharaza

Rzilane

Kot:

Rhouctan

Tbartou

sinant

Phoudan

Boohi assa

Lerer et

Ltrme

A

Al smoun $\sim$ Raghoud

star

Lmater

Kou

Ournakssi

Hater Elbre

Saadi

Boidi

cascuiz

comor

Gaouizi

Lrmar

Lhmer

Lrasi

Lmatar

Messar

Arow

Lkhoumbiz

Beghi assa

Rhoudane

Ourk Htman

rabti

Sibti

Tabil

Hatra

Lmarar
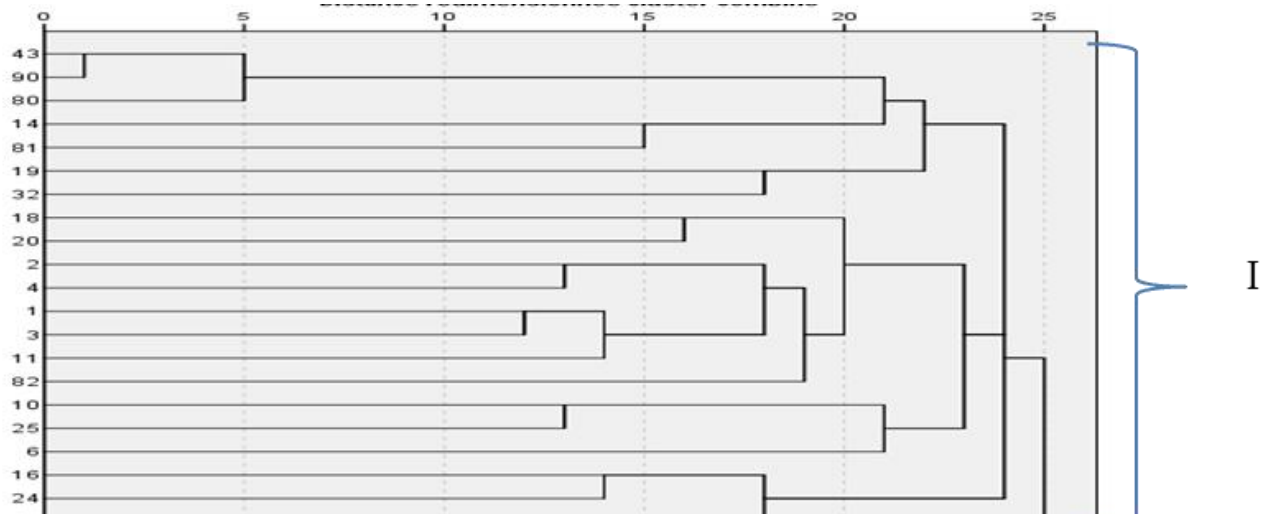

Fig. 5. Representation in cluster of individuals of the north region of Morocco. 


\section{CONCLUSION}

It could be concluded that there are a wide range of variability within the cultivated fig accessions under current study. This diversification could enrich the genetic base of this genus and required more studies to achieve the maximum usefulness from this diversification. Morphological results will be useful in characterizing and to create the first reference and catalogue of the fig accessions.

\section{ACKNOWLEDGMENT}

The authors are grateful to all farmers for providing necessary facilities for conducting this research work.

\section{REFERENCES}

[1] Weiblen GD (2000) Phylogenetic relationships of functionally diocious Ficus (Moraceae) based on ribosomal DNA sequences and morphology. Am J Bot 87(9):13421357.

[2] Zohary D, Hopf M (2000) Domestication of plants in the old world, 3rd edn. Oxford University Press, Oxford.

[3] Storey WB (1975) Figs. In: Janick J, Moore J (eds) Advances in fruit breeding. Purdue University Press, Indiana, pp 568-589

[4] Vidaud J (1997) Le figuier, Centre technique interprofessionnel des fruits et légumes, Paris, France, pp. $31-60$.

[5] Condit, I.J (1955) Fig varieties: a monograph. Ed. Hilgardia, a Journal of Agricultural Science, California Agricultural Experimental Station, $n^{\circ} 11:$ pp 323-538.

[6] Mars M, Marrakchi M, Chelbi T (1998) Multivariate analysis of fig (Ficus carica L.) germplasm southern Tunisia. Acta Hortic 480:75-81

[7] Hedfi J, Trifi M, Salhi Hannachi A, Rhouma A, Marrakchi M (2003) Morphological and isoenzymatic polymorphism in Tunisian fig (Ficus carica L.) collection. Acta Hortic 605:319-325.

[8] Chatti K, Salhi Hannachi A, Mars M, Marrakchi M, Trifi M, (2004) Analyse de la diversité génétique de cultivars tunisiens de figuier (Ficus carica L.) à l'aide de caractèrres morphologiques. Fruits 59 (1):49-61.

[9] Tayou A (1985). Etude technique et économique de la culture du figuier dans la région de Chefchaouen. Mémoire de fin d'études. Institut Agronomique et Vétérinaire Hassan II, Rabat, Maroc.

[10] Crisosto C.H., Bremer V., Ferguson L., Crisosto G.M (2010) Evaluating Quality Attributes of Four Fresh Fig (Ficus carica L.) Cultivars Harvested at Two Maturity Stages. HortScience, 45(4) : 707-710.

[11] Simsek M (2009) Evaluation of selected fig genotypes from South east Turkey. Afr. J. Biotechnol., 8(19) : 4969-4976.

[12] Aljane F., Nahdi S., Essid A (2012) Genetic diversity of some accessions of Tunisian fig tree (Ficus carica L.) based in morphological and chemical traits. J. Nat. Prod. Plant. Resour. , 2 (3): 350-359.
[13] Caliskan O., Polat A.A (2012) Morphological diversity among fig (Ficus carica L.) accessions sampled from the Eastern Mediterranean Region of Turkey. Turk. J. Agric. For., (36): 179-193.

[14] Papadopoulou K., Ehaliotis C., Tourna M., Kastanis P., Karydis I., Zervakis G (2002) Genetic relatedness among dioecious Ficus carica L. cultivars by random amplified polymorphic DNA analysis, and evaluation of agronomic and morphological characters, Genetica (114): 183-194.

[15] Abo-El-Ez A.T., Mostafa R.A.A., Badawy I.F.M (2013) Growth and Productivity of Three Fig (Ficus carica L.) Cultivars Grown Under Upper Egypt Conditions. Aust. J. Basic \& Appl. Sci., 7(2) : 709-714.

[16] Simsek M (2011) A Study on Selection and Idntification of Table Fig Types in East Edge of Firat River. Asian J. Anim. Vet. Adv., 6(3) : 265-273.

[17] Khanfir E (2015) Identification of genetic diversity of Ficus carica : Morphological and molecular characterization of varieties from Kerkennah. Editions Universitaires Européennes. Saarbrücken, Allemagne, 106 p.

[18] Aljane F., Ferchichi A (2008) Pomological Characteristics of Local Fig (Ficus carica L) Cultivars in Southern Tunisia. Acta Hort., (798) :123-128.

[19] Vrhovnik I., Podgornik M., Tomazic I., Prgomet Z., Skrt A (2008) Morphological Characters of Fig Varieties in Istria: 9-75 pp. In The Common Fig (Ficus carica L.) in Istria. Morphological, Molecular and Some Chemical Characteristics. University of Primorska, Science and Research Centre Koper, Publishing House Annales. Project RGFI -Revitalization of Fig Cultivation in Istria, 104 p.

[20] Oukabli, A. and Khadari, B (2005) Caractérisation des variétés polyclonales marocaines de figuiers, Ficus carica L. Fruits 60:1-8. 